\title{
Food and drink consumption at school lunchtime: the impact of lunch type and contribution to overall intake in British 9-10-year-old children
}

\author{
Flo Harrison ${ }^{1, *}$, Amy Jennings ${ }^{2}$, Andy Jones ${ }^{1}$, Ailsa Welch ${ }^{2}$, Esther van Sluijs ${ }^{3}$, \\ Simon Griffin ${ }^{3}$ and Aedín Cassidy ${ }^{2}$ \\ ${ }^{1}$ School of Environmental Sciences, University of East Anglia, Norwich NR4 7JT, UK: ${ }^{2}$ Department of Nutrition, \\ Norwich Medical School, University of East Anglia, Norwich, UK: ${ }^{3}$ Medical Research Council Epidemiology \\ Unit, Institute of Metabolic Science, Addenbrooke's Hospital, Cambridge, UK
}

Submitted 10 December 2010: Accepted 10 August 2011: First published online 22 September 2011

\begin{abstract}
Objective: To examine the differences in dietary intakes of children consuming school meals and packed lunches, the contribution of lunchtime intake to overall dietary intake, and how lunchtime intake relates to current food-based recommendations for school meals.

Design: Cross-sectional analysis of overall intake of macronutrients and food choice from $4 \mathrm{~d}$ food diaries and school lunchtime intake from the two diary days completed while at school.

Setting: Norfolk, UK.

Subjects: One thousand six hundred and twenty-six children (aged 9-10 years) attending ninety Norfolk primary schools.

Results: At school, lunchtime school meal eaters consumed more vegetables, sweet snacks, chips, starchy foods and milk, and less squash/cordial, fruit, bread, confectionery and savoury snacks than packed lunch eaters. These differences were also reflected in the overall diet. On average school meal eaters met the School Food Trust (SFT) food-based standards, while food choices among packed lunch eaters were less healthy. The contribution of food consumed at school lunchtime to overall diet varied by food and lunch type, ranging from $0 \cdot 8 \%$ (milk intake in packed lunches) to $74 \cdot 4 \%$ (savoury snack intake in packed lunches). Conclusions: There were significant differences in the foods consumed by school meal and packed lunch eaters, with food choices among school meal eaters generally in line with SFT standards. The food choices made at school lunchtime make a significant contribution to overall diet.
\end{abstract}

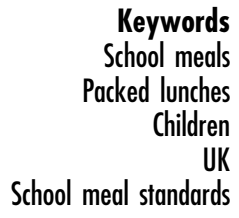

Keywords

School meals

Children

School meal standards
Food consumed at school, and its potential association with childhood obesity, has received considerable attention from the UK media in recent years, with particular emphasis on the quality of meals from school canteens ${ }^{(1)}$. In May 2006 the UK Government announced new standards for school food. Determined by the School Food Trust (SFT), these included the introduction of interim food-based standards for lunches provided by schools in September 2006, which were finalized, almost unchanged, for September $2008^{(2)}$. These replaced previous food-based standards introduced in 2001, prior to which no government guidelines or compulsory standards had been in place ${ }^{(3)}$.

Lunches consumed at school make a significant contribution to food intake, providing $25-33 \%$ of daily energy intake among children of primary school age ${ }^{(4)}$. Hence improvements in school lunches may have an impact on overall diet, potentially leading to improved health outcomes. Indeed, in adolescents, significant differences have been observed in some cardiovascular risk factors (systolic blood pressure, ratio of total cholesterol to HDL cholesterol, plasma glucose, serum insulin, serum folate) between those usually eating school meals, who appear to have slightly lower cardiovascular risk profiles, and those eating packed lunches ${ }^{(5)}$.

There is evidence that the quality of lunches eaten at school varies according to whether the meal is provided by the school (referred to as a 'school meal' throughout this paper, with 'school lunches' referring to any food consumed at school at lunchtime) or brought in from home ('packed lunch'), but neither lunch type has previously been seen to be consistently nutritionally better than the other ${ }^{(6-8)}$. A 1996 survey of Scottish primaryschool children found poorer nutrient profiles among 
those eating school meals. This group typically took a lower proportion of their energy from carbohydrates $(45 \cdot 4 \% v .53 \cdot 2 \%)$ and a higher proportion from fat $(42 \cdot 3 \%$ $v$. 38.8\%) than those eating packed lunches ${ }^{(4)}$. More recently, but prior to the introduction of current standards, Rogers et $a l .{ }^{(7)}$ found nutritional deficiencies in both lunch types that were worse among those eating packed lunches, who had higher intakes of saturated fat $(16 \cdot 2 \%$ of energy $v$. $12.0 \%$ in school meals) and sugar $(20.9 \%$ of energy $v$. $14 \cdot 2 \%)$ and lower intakes of some micronutrients.

Since the introduction of current school lunch standards, two studies ${ }^{(6,8)}$ have compared the quality of school meals and packed lunches in the UK. Both found that school meals are more likely to meet the food-based standards. Rees et al. ${ }^{(6)}$ reported those consuming school meals were more likely to eat a portion of vegetables and fish, and were less likely to eat chocolate bars, savoury snacks, sugary drinks and a portion of fruit. Similarly the $\mathrm{SFT}^{(8)}$ also saw lower consumption of fruit, confectionery, savoury snacks and sugary drinks among those consuming school meals.

Another factor likely to impact on the quality of food consumed in school meals is the degree of choice pupils have at lunchtime ${ }^{(3)}$. The 2001 food-based standards for school meals were framed around providing healthy choices, but these appeared to have little impact on actual intake $^{(3)}$ as children were seen not to take the healthy choices available ${ }^{(6)}$.

Although previous work has compared school meals and packed lunches, much of it was undertaken prior to the introduction of the current UK school meal standards. Furthermore, recent studies have used fairly small samples and have compared only intake at lunchtime on school days. We build on this work by investigating the differences in children's food intake between school meal and packed lunches and the impact of food choice at lunchtime on overall dietary intake among a large, well-characterized sample of 9-10-year-old schoolchildren from Norfolk, UK, who completed detailed food diaries. We examine how the food and drink consumed at lunchtime on school days contributes to overall intake and consider whether school lunches are meeting current food-based standards.

\section{Methods}

\section{Recruitment}

The SPEEDY study (Sport, Physical activity and Eating behaviour: Environmental Determinants in Young people) was instigated to investigate individual and collective correlates of diet and physical activity behaviour of Year 5 (aged 9-10 years) children across the county of Norfolk, UK. Ethical approval for the SPEEDY study was obtained from the University of East Anglia local research ethics committee. The study's methods are described in detail elsewhere $^{(9)}$ and so are only briefly recounted here.
Schools across Norfolk with at least twelve Year 5 pupils were sampled according to a stratification by urban/rural status ${ }^{(10)}$. Ninety-two schools took part in the study, and 2064 children were recruited into SPEEDY; $57 \%$ of the 3619 invited to participate. Data collection was performed during the summer term (April to July) of 2007. Teams of trained research assistants performed measurements at participating schools according to standard operating procedures, oversaw the completion of questionnaires, and distributed food diaries and parental questionnaires for later completion.

\section{Dietary assessment}

Participating children were asked to complete an unweighed $4 \mathrm{~d}$ food and drink diary, with the assistance of their parents. Diaries were completed over four consecutive days; either Thursday to Sunday or Saturday to Tuesday depending on when measurement took place at a child's school. A 4 d diary was deemed sufficient to determine mean dietary intake without overburdening participants, while also covering equal numbers of weekdays and weekend days. A short questionnaire at the beginning of the food diary asked children about their usual dietary habits, including which one of the following they usually did at lunchtime on school days: eat a meal from the school canteen, eat a packed lunch brought from home, go home for lunch, or not eat lunch. The diary required children to record all food and drink consumed by time of consumption, and to include estimates of portion size (small, medium or large, or specific unit such as a packet of crisps). Guidance on the completion of the diary was given to the children by the research assistants and full written instructions were included for parents.

Food and nutrient intakes were calculated from the food diaries using WISP nutritional analysis software version $3 \cdot 0$ (Tinuviel Software, Warrington, UK) using values from McCance and Widdowson's The Composition of Foods, 6th edition ${ }^{(11)}$, and portions sizes were estimated from previously published data ${ }^{(12-14)}$. The data entered into WISP were reviewed by a dietitian who checked for errors and consistency. For these analyses only those with $4 \mathrm{~d}$ worth of data, with at least one school day, were included. From these data we estimated $4 \mathrm{~d}$ mean intakes of energy, fat, protein, carbohydrates and fibre (NSP). The intakes of key food types, selected to be comparable with the SFT interim food-based standards for school lunches ${ }^{(2)}$ which were in place at the time of the data collection, were estimated as the mean intake of foods consumed between 12.00 and 14.00 hours on school days. This time period covered the lunch-breaks, but no other break-times at all schools. As we did not have a record of whether children were at school on any given day, school days were defined as weekdays during term time.

Under-reporting of energy intake was assessed by calculating the ratio of reported energy intake (EI) to estimated energy requirements (EER), which were estimated 
using equations from the FAO/WHO/United Nations University Expert Consultation Report on Human Energy Requirements $^{(15)}$. A 95\% confidence interval for the accuracy of EI:EER was calculated by taking into account the amount of variation inherent in the methods used to estimate EI and EER ${ }^{(16)}$. For the SPEEDY data the 95\% confidence interval for EI:EER was $0 \cdot 71,1 \cdot 30$; therefore those reporting an EI of less than $71 \%$ of EER were defined as under-reporters. So as not to distort dietary intake data by excluding children who under-reported energy intake, the EI:EER ratio was included as a continuous variable in all statistical models ${ }^{(17)}$.

\section{Child and family covariates}

As individual factors are known to be associated with dietary intake ${ }^{(18)}$, we included gender and measures of adiposity and socio-economic status (SES) in our analyses. Height was recorded to the nearest millimetre using a Leicester height measure, and a non-segmental Tanita scale (type TBF-300A) was used to measure weight. BMI (= weight $\left.(\mathrm{kg}) /[\text { height }(\mathrm{m})]^{2}\right)$ was calculated for all participants with valid height and weight data. SES was measured based on educational attainment from the questionnaire completed by the parents/carers of all participating children. The individual completing the questionnaire (the mother on $86 \%$ of occasions) was asked to indicate their highest educational qualification. Answers to this question were grouped into four categories: (i) no qualifications/school leaving certificate; (ii) GCSE or equivalent; (iii) A-Level or equivalent; and (iv) degree or higher.

\section{School policies}

The head teacher at each participating school was asked to complete a questionnaire which included questions on physical activity and food-related facilities, policies and learning opportunities. This included a question on whether children had any choice in the food they obtained from the school canteen, with the options of: (i) 'Yes, they can choose what they want on the day', (ii) 'Yes, menus are sent to parents and choices can be made in advance', or (iii) 'No'. The questionnaire also asked what percentage of all pupils at the school ate school meals, and whether a hot meal was available every day.

\section{Statistical analysis}

All statistical analyses were performed in 2010 using the Intercooled STATA statistical software package version 11 (2009; StataCorp LP, College Station, TX, USA). We derived mean intake values of the nutrients and food types studied adjusted for sex, BMI, SES, under-reporting and, for food types, total energy intake. Because schools were used as the sampling units in SPEEDY, multilevel regression models (xtreg command in STATA) were used to account for potential school-level clustering in outcomes, with child at level 1 and nested within schools at level 2. We modelled the intake of each nutrient and food type based on the covariates and a variable indicating lunch type (school meal or packed lunch), and used the estimates to predict dietary intake means at mean values of the independent variables for each lunch type group. Adjusted mean intakes were derived in this manner for daily consumption over all four diary days and for lunchtime (12.00-14.00 hours) consumption on school days. To calculate the variance between schools, for the school day models intra-class correlations (ICC) were derived by calculating the estimated between-school variance as a percentage of the estimate of total variance. The moderating effect of choice in school meals was assessed by fitting an interaction term between these two factors (meal choice and lunch type). Where interactions were statistically significant at $P<0 \cdot 1$ they were further investigated in stratified models.

\section{Results}

Of the 2064 children recruited in the SPEEDY study, 1859 provided valid food diaries. However, a further 233 were excluded as 141 did not complete all four days of the diary, forty completed the diary over the half-term week and so did not include any school days, forty-five did not report their usual school lunch type, and valid height and weight data were not available for seven children. To prevent further loss of cases SES was imputed to the modal category, GCSE or equivalent, for seventy-five participants who were missing these data. This resulted in a final sample of 1626 children $(78.8 \%$ of SPEEDY participants), attending ninety schools (two schools were excluded as none of their pupils met the inclusion criteria for these analyses). There was no difference between those included and excluded in terms of sex, BMI and SES (all $P>0.05$ ); however, those excluded reported lower energy intake, had greater under-reporting and were more likely to eat school meals $(P<0 \cdot 01)$.

Characteristics of the pupils included in the present analyses are summarized in Table 1 . Slightly more girls (56\%) than boys were recruited to the study, and were thus included in the analyses. Girls generally had higher BMI than boys $(P<0 \cdot 05)$, but there were no significant gender differences in SES, lunch type or under-reporting. All participants reported usually eating either a school meal ( $n$ 399) or a packed lunch ( $n$ 1227). Across the ninety schools, mean uptake of school meals as reported by the head teacher was $32 \cdot 4$ (sD $14 \cdot 5$ ) \%. The uptake of school meals by school in the analysis sample ranged from $0 \%$ to $100 \%$, with a mean of 24.5 (sD 20.4) \%. In terms of choice offered, twenty-three schools $(25 \cdot 6 \%)$ gave pupils no choice in school meals, thirty-two (35.6\%) gave choice in advance, and thirty-four (37.8\%) gave pupils some choice on the day (one school did not answer this question). All schools offered a hot meal every day. 
Table 1 Characteristics of the participants included in the present analyses: British children ( $n$ 1626) aged 9-10 years from the SPEEDY (Sport, Physical activity and Eating behaviour: Environmental Determinants in Young people) study

\begin{tabular}{|c|c|c|c|c|c|c|}
\hline & \multicolumn{2}{|c|}{ All } & \multicolumn{2}{|c|}{ Girls } & \multicolumn{2}{|c|}{ Boys } \\
\hline & Mean or $n$ & SD or $\%$ & Mean or $n$ & SD or $\%$ & Mean or $n$ & SD or $\%$ \\
\hline Number of participants & 1626 & 100 & 910 & 56 & 716 & 44 \\
\hline Age (years) & $10 \cdot 25$ & 0.31 & $10 \cdot 25$ & 0.31 & $10 \cdot 24$ & $0 \cdot 31$ \\
\hline BMI $\left(\mathrm{kg} / \mathrm{m}^{2}\right) \dagger$ & $18 \cdot 21$ & $3 \cdot 12$ & $18 \cdot 51$ & $3 \cdot 28$ & $17 \cdot 83$ & $2 \cdot 84$ \\
\hline \multicolumn{7}{|c|}{ Highest educational qualification of parent $(n, \%)$} \\
\hline None & 107 & $6 \cdot 6$ & 62 & $6 \cdot 8$ & 45 & $6 \cdot 3$ \\
\hline GCSE or equivalent & 873 & $53 \cdot 7$ & 495 & $54 \cdot 4$ & 378 & $52 \cdot 8$ \\
\hline A-Level or equivalent & 390 & $24 \cdot 0$ & 220 & $24 \cdot 2$ & 170 & $23 \cdot 7$ \\
\hline Degree or higher & 256 & $15 \cdot 7$ & 133 & $14 \cdot 6$ & 123 & $17 \cdot 2$ \\
\hline \multicolumn{7}{|c|}{ Usual type of lunch on school day $(n, \%)$} \\
\hline School meal & 399 & $24 \cdot 5$ & 214 & $23 \cdot 5$ & 185 & $25 \cdot 8$ \\
\hline Packed lunch & 1227 & $75 \cdot 5$ & 696 & $76 \cdot 5$ & 531 & $74 \cdot 2$ \\
\hline Under-reportersł & 332 & $20 \cdot 4$ & 176 & $19 \cdot 3$ & 156 & $21 \cdot 8$ \\
\hline
\end{tabular}

tDifference between girls and boys was statistically significant at $P<0.05$.

fUnder-reporting defined as reported energy intake $<71 \%$ of estimated energy requirements.

Table 2 Adjusted mean dietary intake over four whole days, by reported usual school lunch type: British children ( $n$ 1626) aged 9-10 years from the SPEEDY (Sport, Physical activity and Eating behaviour: Environmental Determinants in Young people) study

\begin{tabular}{|c|c|c|c|c|}
\hline & \multicolumn{2}{|c|}{ School meal ( $n$ 399) } & \multicolumn{2}{|c|}{ Packed lunch ( $n$ 1227) } \\
\hline & Meant & SE & Meant & $\mathrm{SE}$ \\
\hline Energy (kJ) & $7338 \cdot 1$ & $16 \cdot 8$ & $7357 \cdot 3$ & $11 \cdot 1$ \\
\hline$\%$ energy from fat & $36 \cdot 8$ & 0.2 & $37 \cdot 0$ & 0.2 \\
\hline$\%$ energy from carbohydrates & $48 \cdot 7$ & $0 \cdot 3$ & $48 \cdot 8$ & $0 \cdot 2$ \\
\hline$\%$ energy from protein & $14 \cdot 6$ & $0 \cdot 1$ & $14 \cdot 2$ & $0 \cdot 1$ \\
\hline NSP $(g) \ddagger$ & $11 \cdot 0$ & $0 \cdot 1$ & $10 \cdot 7$ & $0 \cdot 1$ \\
\hline Energy density & $7 \cdot 2$ & $0 \cdot 1$ & $7 \cdot 6$ & $0 \cdot 0$ \\
\hline Fruit $(\mathrm{g}) \ddagger$ & $90 \cdot \overline{3}$ & $4 \cdot 5$ & $100 \cdot 2$ & $2 \cdot 9$ \\
\hline Vegetables $(\mathrm{g}) \ddagger$ & $112 \cdot 0$ & $3 \cdot 2$ & $96 \cdot 7$ & $2 \cdot 1$ \\
\hline Fruit and vegetables (g) & $202 \cdot 3$ & $5 \cdot 9$ & $196 \cdot 9$ & $3 \cdot 7$ \\
\hline Fruit juice $(\mathrm{g})$ & $139 \cdot 9$ & $7 \cdot 6$ & $134 \cdot 1$ & $4 \cdot 6$ \\
\hline Carbonated drinks (g) & $83 \cdot 8$ & 5.9 & $81 \cdot 1$ & $3 \cdot 7$ \\
\hline Squash/cordial (g)‡ & $150 \cdot 1$ & $11 \cdot 4$ & $191 \cdot 0$ & $7 \cdot 1$ \\
\hline Savoury snacks $(\mathrm{g}) \neq \S$ & $10 \cdot 2$ & 0.6 & $14 \cdot 0$ & 0.4 \\
\hline Sweet snacks $(\mathrm{g}) \neq \|$ & $86 \cdot 2$ & $2 \cdot 4$ & $75 \cdot 5$ & 1.5 \\
\hline Confectionery $(\mathrm{g}) \neq$ & $17 \cdot 7$ & $1 \cdot 0$ & $21 \cdot 5$ & $0 \cdot 6$ \\
\hline Chips (g)‡ & $37 \cdot 7$ & $1 \cdot 8$ & $30 \cdot 3$ & $1 \cdot 2$ \\
\hline Bread $(\mathrm{g}) \ddagger$ & $60 \cdot 2$ & $1 \cdot 6$ & $72 \cdot 0$ & $1 \cdot 0$ \\
\hline Starchy foods $(\mathrm{g}) \mathrm{t \dagger}$ & $161 \cdot 7$ & $3 \cdot 3$ & $159 \cdot 2$ & $2 \cdot 2$ \\
\hline  & $87 \cdot 8$ & $5 \cdot 5$ & $88 \cdot 0$ & $3 \cdot 1$ \\
\hline
\end{tabular}

tMeans adjusted for sex, BMI, socio-economic status, ratio of reported energy intake to estimated energy requirements, and, for food types only, total energy.

‡Difference in mean whole-day intake between school meal and packed lunch eaters was statistically significant at $P<0.05$.

§Savoury snacks include: potato, cereal, soya, nuts, seeds, fruit or vegetable snacks with added salt or sugar.

ISweet snacks include: cakes, biscuits, puddings and desserts.

-Confectionery includes: sweets and chocolate, or products containing, coated or flavoured by chocolate.

t+Starchy foods include: bread, pasta, rice, couscous, noodles, potatoes, sweet potatoes, yams, millet, cornmeal and other cereals not cooked in oil.

¥¥Skimmed and semi-skimmed milk only.

Participants reported consuming an average of 7355 (sE 38) $\mathrm{kJ} / \mathrm{d}$, with $48 \cdot 7$ (se $0 \cdot 12$ ) \% of energy coming from carbohydrates, $37 \cdot 0$ (SE $0 \cdot 11$ ) \% from fats and $14 \cdot 3$ (SE $0 \cdot 06) \%$ from protein. Average daily intake of NSP was $10 \cdot 8$ ( $\mathrm{se} 0 \cdot 07$ ) g. Adjusted mean dietary intakes of participants are given by lunch type in Tables 2 and 3. The adjusted mean differences in food consumption between the two lunch types are displayed in Fig. 1. In terms of nutrient intake (Table 2), school meal eaters consumed more NSP, acquired a higher percentage of energy from protein and had a less energy-dense diet than packed lunch eaters (all $P<0 \cdot 05$ ). There were no statistically significant differences in total energy consumption or percentage of energy from fat or carbohydrates between lunch types. The contribution of lunchtime food intake to average daily food intakes varied by lunch type; the school meal group ate much of their vegetables $(42 \cdot 5 \%)$, sweet snacks (46.9\%) and chips (61.1\%) during school lunches, while those taking packed lunch consumed $74 \cdot 4 \%$ of their intake of savoury snacks, $64 \cdot 0 \%$ of their 
Table 3 Adjusted mean dietary intake at lunchtime on school days, by reported usual school lunch type: British children ( $n$ 1626) aged 9-10 years from the SPEEDY (Sport, Physical activity and Eating behaviour: Environmental Determinants in Young people) study

\begin{tabular}{|c|c|c|c|c|c|c|c|c|c|c|}
\hline & \multicolumn{2}{|c|}{$\begin{array}{l}\text { SFT interim food-based } \\
\text { standards }\end{array}$} & \multicolumn{3}{|c|}{$\begin{array}{l}\text { School meal } \\
\quad(n \text { 399) }\end{array}$} & \multicolumn{3}{|c|}{$\begin{array}{l}\text { Packed lunch } \\
\quad(n \text { 1227) }\end{array}$} & \multicolumn{2}{|c|}{$\begin{array}{l}\text { School-level } \\
\text { variance }\end{array}$} \\
\hline & $\begin{array}{l}\text { Standard } \\
\text { (per lunchtime) }\end{array}$ & $\begin{array}{l}\text { Equivalent } \\
\text { gramst }\end{array}$ & Mean‡ & SE & $\begin{array}{l}\% \text { of daily } \\
\text { intake }\end{array}$ & Mean‡ & SE & $\begin{array}{l}\% \text { of daily } \\
\text { intake }\end{array}$ & ICC & \\
\hline Energy (kJ) & & & $2435 \cdot 4$ & $40 \cdot 5$ & $33 \cdot 2$ & $2549 \cdot 7$ & $27 \cdot 5$ & $34 \cdot 7$ & $4 \cdot 9$ & ** \\
\hline Fruit $(\mathrm{g})$ & At least one portion & 40 & $20 \cdot 3$ & $3 \cdot 2$ & $22 \cdot 5$ & $51 \cdot 0$ & $2 \cdot 1$ & $50 \cdot 9$ & $4 \cdot 1$ & ** \\
\hline Vegetables (g) & At least one portion & 40 & $47 \cdot 6$ & $2 \cdot 6$ & $42 \cdot 5$ & $20 \cdot 9$ & $2 \cdot 1$ & $21 \cdot 6$ & $15 \cdot 8$ & ** \\
\hline Fruit and vegetables $(\mathrm{g})$ & At least two portions & 80 & $69 \cdot 6$ & $4 \cdot 0$ & $34 \cdot 4$ & $71 \cdot 9$ & $2 \cdot 9$ & $36 \cdot 5$ & $7 \cdot 5$ & ** \\
\hline Fruit juice $(\mathrm{g})$ & $\begin{array}{l}\text { A 'Healthier drink'; } \\
\text { consumption unlimited }\end{array}$ & $\mathrm{N} / \mathrm{A}$ & $46 \cdot 5$ & $4 \cdot 9$ & $33 \cdot 2$ & $46 \cdot 9$ & $3 \cdot 2$ & $35 \cdot 0$ & $3 \cdot 3$ & ** \\
\hline Carbonated drink (g) & Not allowed & 0 & $3 \cdot 0$ & $1 \cdot 0$ & $3 \cdot 6$ & 1.9 & 0.6 & $2 \cdot 3$ & $0 \cdot 0$ & NS \\
\hline Squash/cordial (g) & Not allowed & 0 & $20 \cdot 3$ & $5 \cdot 7$ & $13 \cdot 5$ & $82 \cdot 7$ & 3.6 & $43 \cdot 3$ & $2 \cdot 7$ & $\star *$ \\
\hline Savoury snacks $(\mathrm{g}) \S$ & Not allowed & 0 & $2 \cdot 5$ & 0.5 & $24 \cdot 4$ & $10 \cdot 4$ & $0 \cdot 4$ & $74 \cdot 4$ & $4 \cdot 0$ & ** \\
\hline Sweet snacks $(\mathrm{g}) \|$ & Not covered by standards & $\mathrm{N} / \mathrm{A}$ & $40 \cdot 5$ & $1 \cdot 8$ & $46 \cdot 9$ & $22 \cdot 6$ & $1 \cdot 2$ & $30 \cdot 0$ & $6 \cdot 1$ & ** \\
\hline Confectionery (g) & Not allowed & 0 & $2 \cdot 8$ & 0.7 & $15 \cdot 8$ & $11 \cdot 0$ & $0 . \overline{4}$ & $51 \cdot 0$ & 0.0 & NS \\
\hline Chips (g) & Not covered by standards & $\mathrm{N} / \mathrm{A}$ & $23 \cdot 0$ & $1 \cdot 4$ & $61 \cdot 1$ & $6 \cdot 1$ & $1 \cdot 1$ & $20 \cdot 2$ & $19 \cdot 5$ & ** \\
\hline Bread (g) & Provided every day & $\mathrm{N} / \mathrm{A}$ & $19 \cdot 2$ & $1 \cdot 4$ & $31 \cdot 9$ & $46 \cdot 1$ & $1 \cdot 0$ & $64 \cdot 0$ & $4 \cdot 4$ & ** \\
\hline Starchy foods $(g)+t$ & Provided every day & $\mathrm{N} / \mathrm{A}$ & $61 \cdot 6$ & 1.9 & $38 \cdot 1$ & $54 \cdot 7$ & $1 \cdot 3$ & $34 \cdot 4$ & $4 \cdot 6$ & ** \\
\hline Milk (g)‡¥ & $\begin{array}{l}\text { A 'Healthier drink'; } \\
\text { consumption unlimited }\end{array}$ & $\mathrm{N} / \mathrm{A}$ & $5 \cdot 9$ & 0.9 & $6 \cdot 7$ & 0.7 & 0.5 & 0.8 & 0.0 & NS \\
\hline
\end{tabular}

ICC, intra-class correlation (percentage of variance at the school level in multilevel model for lunchtime intake on school days; ${ }^{\star \star} P<0 \cdot 01$ ); N/A, not applicable. tEquivalent grams based on estimated portion sizes used for data entry.

¥Means adjusted for sex, BMI, socio-economic status, ratio of reported energy intake to estimated energy requirements, and, for food types only, total energy. §Savoury snacks include: potato, cereal, soya, nuts, seeds, fruit or vegetable snacks with added salt or sugar.

ISweet snacks include: cakes, biscuits, puddings and desserts.

$\uparrow$ Confectionery includes: sweets and chocolate, or products containing, coated or flavoured by chocolate.

t+Starchy foods include: bread, pasta, rice, couscous, noodles, potatoes, sweet potatoes, yams, millet, cornmeal and other cereals not cooked in oil.

¥¥Skimmed and semi-skimmed milk only.

bread and $51.0 \%$ of their average daily confectionery intake at lunchtime (Table 3).

Where applicable Table 3 gives the SFT food-based standards for the relevant food groups along with the equivalent grams per lunchtime meal based on the portion sizes used during data entry. Among school meal eaters, mean fruit and fruit and vegetable intakes were below the level set by the guidelines $(20.3 \mathrm{~g} \mathrm{v} .40 .0 \mathrm{~g}$ and $69 \cdot 6 \mathrm{~g} v \cdot 80 \cdot 0 \mathrm{~g}$, respectively). Packed lunch eaters' mean consumption of vegetables and fruit and vegetables were also below SFT standards $(20.9 \mathrm{~g} v .40 .0 \mathrm{~g}$ and $71.9 \mathrm{~g} v$. $80.0 \mathrm{~g}$, respectively), and among both lunch types there was consumption of prohibited foods (carbonated drinks, squash/cordial, savoury snacks and confectionery) which was generally greater in those eating a packed lunch. The lunchtime intakes of most food types varied significantly at the school level, with ICC (Table 3 ) of up to $19.5 \%$ (for intake of chips at lunchtime). However, no statistically significant interactions were observed between lunch type and meal choice, so no further stratification was performed.

Figure 1 shows the adjusted differences in food intakes between those usually eating school meals $v$. packed lunches. It illustrates that overall, and at school lunchtime, school meal eaters consumed more vegetables, sweet snacks and chips than packed lunch eaters. Packed lunch eaters consumed more savoury snacks, confectionery, bread, fruit and squash/cordial. School meal eaters also consumed statistically significantly more starchy food and milk than packed lunch eaters at school lunchtime, although these differences were not seen in overall intake.
Some of the differences in mean consumption were considerably larger at school lunchtimes than overall, with the school meal group eating $27 \mathrm{~g}$ more vegetables (compared with $15 \mathrm{~g}$ more overall) and packed lunch eaters consuming $62 \mathrm{~g}$ more squash/cordial and $31 \mathrm{~g}$ more fruit (compared with $41 \mathrm{~g}$ and $10 \mathrm{~g}$ overall, respectively).

\section{Discussion}

The present study investigated the associations between lunch type at school and dietary intake in 9-10-year-old children. The contribution of school lunchtime intake to overall intake varied by lunch type and food choice, and significant differences in food consumption were observed both at lunchtime on school days and over the whole day between school meal and packed lunch eaters.

Our findings of greater vegetable consumption among school meal eaters and greater fruit consumption among packed lunch eaters are comparable with others who have compared school meals and packed lunches since the introduction of the current food-based standards for school lunches ${ }^{(6,19)}$. On average, both groups met total fruit and vegetable intake recommendations for school meals (two portions; $80 \mathrm{~g}^{(2)}$ ) when fruit juices were included, but only the school meal group reported consuming one whole portion $(40 \mathrm{~g})$ of vegetables. These differences were clearer during lunchtime on school days, but were also apparent over the whole day. Steps to increase vegetable consumption among packed lunch eaters may therefore be appropriate. 


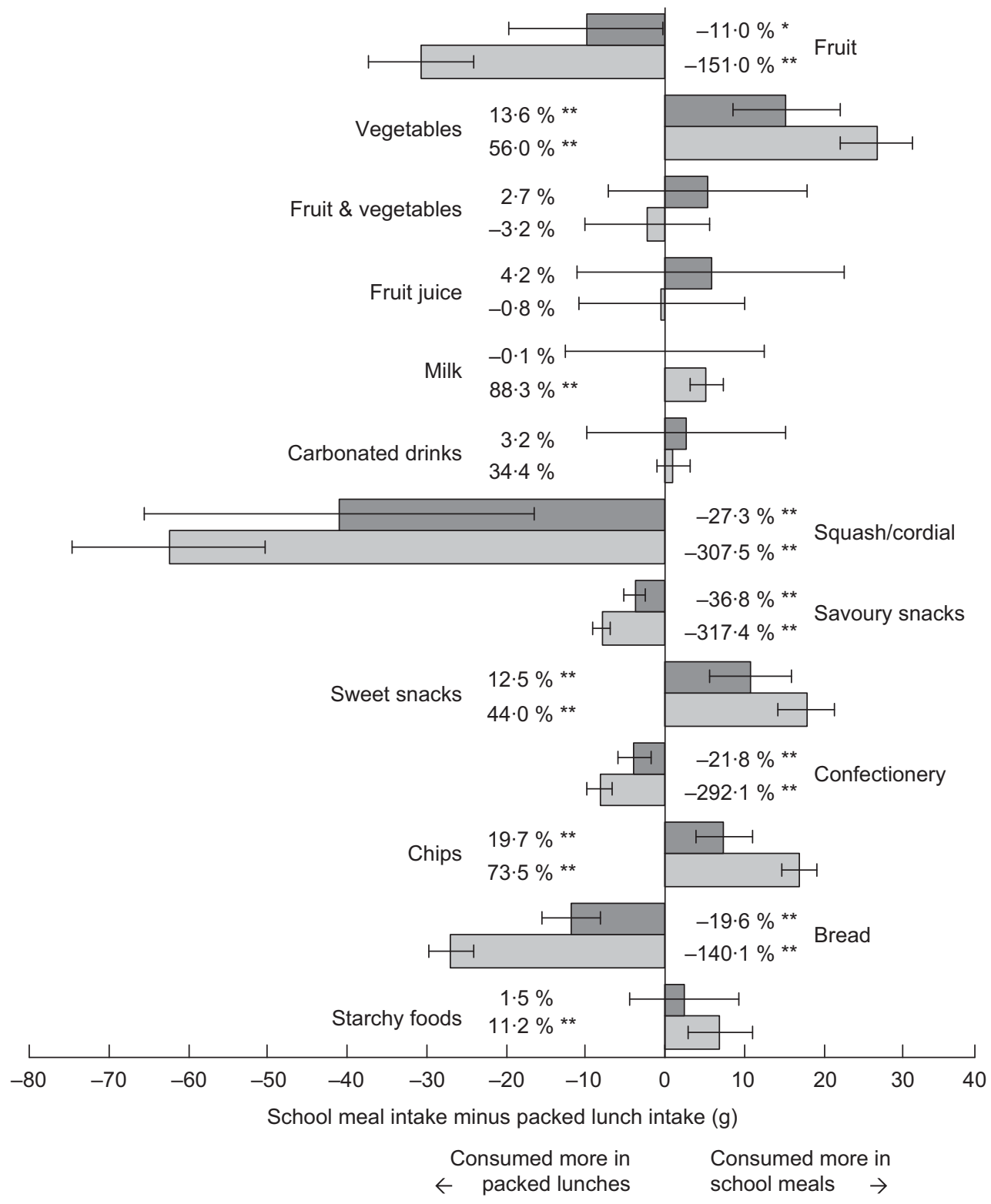

Fig. 1 Differences in food intakes between those usually eating school meals and those usually eating packed lunches ( $\square$, mean daily intake over all diary days; $\square$, mean lunchtime (12.00-14.00 hours) intake on school days): British children ( $n$ 1626) aged 9-10 years from the SPEEDY (Sport, Physical activity and Eating behaviour: Environmental Determinants in Young people) study. Bars are difference between means, with $95 \%$ confidence interval represented by error bars, adjusted for sex, BMI, socio-economic status, under-reporting and total energy. Values beside bars are adjusted differences between means as a percentage of the school meal mean. Adjusted difference between school meals and packed lunches was statistically significant: ${ }^{\star} P<0 \cdot 05,{ }^{\star \star} P<0 \cdot 01$

SFT standards promote the provision of 'healthier' drinks, including fruit juice and skimmed and semiskimmed milk, while prohibiting that of others such as sugary drinks. In these analyses fruit juice intake appeared to make an important contribution to overall fruit and vegetable intake but did not differ between the two lunch types. Milk consumption was significantly higher among the school meal group at lunchtime but average consumption was very low in both groups $(5.9 \mathrm{~g}$ and $0.7 \mathrm{~g})$. Consumption of carbonated drinks at lunchtime on school days was also low in both groups. A striking difference in beverage consumption was seen in the consumption of squash/cordial; packed lunch eaters drank almost four times as much as school meal eaters. Such drinks are prohibited by the SFT, but the standards do not apply to packed lunches. The same pattern of beverage consumption as in the current study was reported by the $\mathrm{SFT}^{(19)}$, who found that school meal eaters drank 'healthier' drinks exclusively, compared with only $69 \%$ of packed lunch eaters.

SFT standards are focused around savoury snacks and confectionery, neither of which are permitted in school meals ${ }^{(20)}$. In accordance with these recommendations, we saw much lower consumption of both these food types among school meal eaters, both at lunchtime on 
school days and over the whole day, compared with packed lunch eaters. The fat, sugar and salt contents of these foods could lead to similar nutritional discrepancies as those reported by Rogers et al. ${ }^{(7)}$; higher intakes of saturated fat $(16 \cdot 2 \%$ of energy in packed lunches $v$. $12.0 \%$ in school meals), sugar $(20.9 \%$ of energy $v$. $14 \cdot 2 \%$ ) and $\mathrm{Na}(805 \mathrm{mg} v .607 \mathrm{mg}$ ). However, we also considered a third group of foods, sweet snacks, including cakes, biscuits, puddings and desserts, which are not explicitly covered by the SFT guidelines. Such foods may form part of a school meal menu where their presence has been associated with higher BMI among pupils ${ }^{(21)}$. We observed that the school meal group consumed significantly more of these than packed lunch eaters. For all these food types, the differences seen at lunchtime on school days were also apparent in overall diet, and school lunch appeared to make a substantial contribution to overall consumption, especially for packed lunch eaters, who consumed $74 \cdot 4 \%$ of their savoury snacks and $51 \cdot 0 \%$ of their confectionery during this period. This raises the possibility that reducing the consumption of these foods at lunchtime could have an impact on overall intake.

At the time of our survey, food-based recommendations for school lunches required that starchy foods (not cooked in oil) be provided to children every day, with bread made available as an extra item. We observed that school meal eaters consumed more starchy foods compared with packed lunch eaters, although a lower proportion of that was from bread. Neither lunch group consumed a full daily portion of starchy foods (based on average portion sizes of $80 \mathrm{~g}$ of rice and $100 \mathrm{~g}$ of mashed potato $\left.^{(13)}\right)$. Starchy foods are promoted as a means of satiating hunger without excessive consumption of fat $^{(2)}$, and higher consumption may help children meet the SFT recommendation of at least $50 \%$ of food energy coming from carbohydrates ${ }^{(22)}$. Although chips are not specifically part of the current school lunch recommendation, they were considered here as such deep-fried, high-fat foods have been implicated as a potential contributor to obesity $^{(23)}$ and their presence on school menus has been associated with higher BMI among pupils ${ }^{(21)}$. Unsurprisingly, the school meal group consumed more chips, both at lunchtime and over the whole day, although the average weight consumed at lunchtime is quite small; $23.0 \mathrm{~g}$ for a school meal, which equates to roughly a portion every $3.9 \mathrm{~d}$, based on a typical portion size of $90 \mathrm{~g}^{(13)}$. Some chips also appeared to be eaten by the packed lunch group at school lunchtime. This could indicate that some the SPEEDY participants who reported usually eating packed lunches actually had a school meal on one or more of the food diary days or that, in addition to eating a packed lunch, they obtained food from the school canteen.

The results of the current study demonstrate that the food eaten at lunchtime in schools has an impact on children's food intake. Lunchtime intakes of all food types, except carbonated drinks, milk and confectionery, showed statistically significant variation at the school level, which contributed up to $19.5 \%$ (chips) of the overall variation in intake. This is perhaps unsurprising given that schools are likely to provide largely the same foods to all children taking school meals, but may also indicate that the choices schools make about the foods they provide are associated with children's intake. No significant interactions were seen between school meal and pupil choice in the current study. The lack of an interaction could be explained by the relatively small numbers in the school meal group (399 school meal eaters compared with 1227 packed lunch eaters) so that once children had been divided into the three choice categories, the numbers could have been too low to detect differences in intake. The provision of pupil choice has been suggested as a potential barrier to improved dietary intake in school meals ${ }^{(3)}$. This is likely to be dependent on the nature of the choices given, and future studies may collect more detailed information about the foods offered by schools to further investigate this.

The present study has a number of strengths and weaknesses. In terms of strengths, we recruited a large number of schools and pupils to the study, and collected a range of measurements from them. We assessed their dietary intake using detailed diet diaries over four whole days (not just during school hours), and included both two weekend days and two weekdays. However, the two school days recorded were not sufficient to give a reliable picture of typical nutrient intake ${ }^{(24)}$, and so our analysis focused on the types of foods consumed.

Although food diaries give a valid measure of food intakes in this age group ${ }^{(25)}$, the diary used in the SPEEDY study was not validated. We did not ask participants to weigh the food and drink they consumed and children have been seen to experience difficulty in estimating portion sizes ${ }^{(26)}$. Under-reporting is a problem in selfreported dietary assessment but we were able to adjust for under-reporting of energy intake. Another weakness is that we did not know if the children had actually been at school on a given weekday or which lunch type they had, only the type of lunch they reported usually consuming, which may have led to some misclassification. However, these potential errors are likely to result in an attenuation of differences between the two groups, and so are unlikely to explain the differences in intake we observed.

In terms of generalizability, the SPEEDY schools and children were broadly representative of the Norfolk population, although with a slightly higher proportion of girls and a lower proportion of obese children taking part ${ }^{(9)}$. However, schools in Norfolk have a low proportion of non-white pupils, which potentially limits the generalizability of our findings to more ethnically diverse populations.

In conclusion we found statistically significant differences in food intake between children consuming school meals and packed lunches and these differences were also observed in overall diet. On average those usually taking 
school meals met current food-based standards for school lunches, while the food choices of packed lunch eaters typically fell short. The uptake of school meals was low (less than $25 \%$ in this sample, but currently just over $40 \%$ in English primary schools ${ }^{(27)}$ ), so it appears that more needs to be done to encourage similar standards in packed lunches. School lunches appear to have an impact on overall diet, but further work is needed to establish how this translates into nutrient intakes and health outcomes.

\section{Acknowledgements}

This work was supported by the National Prevention Research Initiative (NPRI; http://www.npri.org.uk), which funded the SPEEDY study. NPRI consists of the following Funding Partners: British Heart Foundation; Cancer Research UK; Department of Health; Diabetes UK; Economic and Social Research Council; Medical Research Council; Research and Development Office for the Northern Ireland Health and Social Services; Chief Scientist Office, Scottish Executive Health Department; Welsh Assembly Government; and World Cancer Research Fund. The authors declare no conflict of interest. F.H. conceived the study and its design, performed the statistical analysis and drafted the manuscript. All authors were involved with the study design and data interpretation, made critical revisions of the paper and provided approval for its publication. The authors thank the schools, the children and their parents for their participation in the SPEEDY study. They also thank everyone who helped with the data collection and Norfolk County Council Children's Services for their invaluable input and support.

\section{References}

1. Burgess A (2010) Media risk campaigning in the UK: from mobile phones to 'Baby P'. J Risk Res 13, 59-72.

2. School Food Trust (2007) A Guide to the Government's New Food-Based Standards for School Lunches. Sheffield: School Food Trust; available at http://www.schoolfood trust.org.uk/UploadDocs/Library/Documents/School-foodtrust.pdf

3. Nelson M, Lowes K \& Hwang V (2007) The contribution of school meals to food consumption and nutrient intakes of young people aged 4-18 years in England. Public Health Nutr 10, 652-662

4. Ruxton C, Kirk T \& Belton N (1996) The contribution of specific dietary patterns to energy and nutrient intakes in 7-8-year-old Scottish schoolchildren. II. Weekday lunches. J Hum Nutr Diet 9, 15-22.

5. Whincup PH, Owen CG, Sattar N et al. (2005) School dinners and markers of cardiovascular health and type 2 diabetes in 13-16 year olds: cross sectional study. BMJ 331, 1060-1061.

6. Rees GA, Richards CJ \& Gregory J (2008) Food and nutrient intakes of primary school children: a comparison of school meals and packed lunches. J Hum Nutr Diet 21, 420-427.

7. Rogers IS, Ness AR, Hebditch K et al. (2007) Quality of food eaten in English primary schools: school dinners vs packed lunches. Eur J Clin Nutr 61, 856-864.

8. School Food Trust (2010) Findings. School Lunch Versus Packed Lunch: Evidence of Compliance with School Food
Standards. Sheffield: School Food Trust; available at http:// www.schoolfoodtrust.org.uk/partners/reports/school-lunchversus-packed-lunch-evidence-of-compliance-with-schoolfood-standards

9. van Sluijs EMF, Skidmore PML, Mwanza K et al. (2008) Physical activity and dietary behaviour in a population-based sample of British 10-year old children: the SPEEDY study (Sport, Physical activity and Eating behaviour: Environmental Determinants in Young people). BMC Public Health 8, 388-399.

10. Bibby P \& Shepherd J (2004) Developing a New Classification of Urban and Rural Areas for Policy Purposes - The Methodology. London: Office of National Statistics; available at http://www.statistics.gov.uk/geography/downloads/ Methodology_Report.pdf

11. Food Standards Agency (2002) McCance \& Widdowson's Composition of Foods, 6th ed. London: Food Standards Agency.

12. Crawley H (2002) Food Portion Sizes, 3rd ed. London: HMSO.

13. Davies OH, Suleiman S, Nicholas J et al. (2008) Food portion weights in primary and secondary school lunches in England. J Hum Nutr Diet 21, 46-62.

14. Wrieden WL, Longbottom PJ, Adamson AJ et al. (2008) Estimation of typical food portion sizes for children of different ages in Great Britain. Br J Nutr 99, 1344-1353.

15. Torun B (2005) Energy requirements of children and adolescents. Public Health Nutr 8, 968-993.

16. Black AE \& Cole TJ (2000) Within- and between-subject variation in energy expenditure measured by the doublylabelled water technique: implications for validating reported dietary energy intake. Eur J Clin Nutr 54, 386-394.

17. Rennie KL, Coward A \& Jebb SA (2007) Estimating underreporting of energy intake in dietary surveys using an individualised method. Br J Nutr 97, 1169-1176.

18. Taylor JP, Evers SE \& McKenna M (2005) Determinants of healthy eating in children and youth. Can J Public Health 96, Suppl. 3, S20-S26.

19. School Food Trust (2007) Children's Lunchtime Choices Following the Introduction of Food-based Standards for School Lunch: Observations from Sheffield Primary Schools. http://www.schoolfoodtrust.org.uk/school-cooks-caterers/ reports/school-lunch-and-learning-behaviour-in-primaryschools-baseline-dietary-data (accessed August 2010).

20. School Food Trust (2008) The food based standards. http:// www.schoolfoodtrust.org.uk/the-standards/the-food-basedstandards (accessed August 2010).

21. Fox MK, Dodd AH, Wilson A et al. (2009) Association between school food environment and practices and body mass index of US public school children. J Am Diet Assoc 109, 2 Suppl., S108-S117.

22. Crawley H (2005) Eating Well at School. Nutritional and Practical Guidelines. St Austell: The Caroline Walker Trust; available from http://www.cwt.org.uk/pdfs/EatingWellat School.pdf

23. Prentice AM \& Jebb SA (2003) Fast foods, energy density and obesity: a possible mechanistic link. Obes Rev 4, 187-194.

24. Bingham SA (1987) The dietary assessment of individuals: methods, accuracy, new techniques and recommendations. Nutr Abstr Rev 57, 705-742.

25. Crawford PB, Obarzanek E, Morrison J et al. (1994) Comparative advantage of 3-day food records over 24-hour recall and 5-day food frequency validates by observation of 9-10 year old girls. J Am Diet Assoc 94, 626-630.

26. Livingstone MBE, Robson PJ \& Wallace JMW (2004) Issues in dietary intake assessment of children and adolescents. Br J Nutr 92, Suppl. 2, S213-S222.

27. School Food Trust (2010) Fifth Annual Survey of Take Up of School Lunches in England. Sheffield: School Food Trust; available at http://www.schoolfoodtrust.org.uk/school-cookscaterers/reports/fifth-annual-survey-of-take-up-of-schoolmeals-in-england 